\title{
Media and the making of migrants
}

[ B O O K REVIEW ]

Hegde, Radha Sarma (2016) Mediating migration. Cambridge: Polity Press. ISBN 9780-7456-4632-9 hbk. Pages $x+161$

This book is about how the migration experience is mediated by new technologies. This mediation is clearly articulated in the introductory chapter which outlines the mediating role that media, technology and other forms of communication plays in the migration experience. As Hegde argues:

"New technologies enable both the disciplining and self-expression of migrant communities worldwide. Devices, technologies and various types of changing media platforms are being widely used by migrants to reinvent and redefine identity" ( $\mathrm{p} 11)$.

This is a topic that has been gaining interest in migration studies and the book is therefore timely and an important contribution to interdisciplinary studies of migration.

The book centres on five "empirical" chapters each considering a different topic from the veil to food blogging, as well as an introduction and conclusion. It is based on a combination of social and political analysis and primary research which makes for lively and diverse reading. They function as illustrations of the emerging social forms that are possible given increasing access to new media.

After an introductory chapter, the first empirical chapter considers the figure of the undocumented migrant. In particular, it unpacks how undocumented migrants are rendered visible and how they claim a voice in the US context. This is the basis for reflections on how
Ingrid Palmary

African Centre for

Migration \& Society

University of the

Witwatersrand

Johannesburg 
documentation shapes our conceptualizations of the nation and how citizenship is at the heart of constructions of the nation. The author shows how irregularity is produced through technologies that in turn shape and are shaped by border control systems.

The second empirical chapter looks at how citizens are invited to participate, through technology such as social networking and reddit, in the surveillance of foreigners in the age of terrorist attacks - a surveillance shaped by race and religious markers. Hedge argues that the recognition and categorization of otherness is facilitated by the rapid flow of information through social media. Using the Boston Marathon bombing as an example she argues that patriotism is performed in digitized spaces and that, far from an automatic good, social media can operate in highly undemocratic ways. This was a particularly interesting chapter for its rich analysis and it attention to a very topical issue, namely the use of social media and its revolutionary / repressive potential.

The next chapter looks at the veil in western society and considers how such gendered representations act as a litmus test of ideology, reflecting one's credentials on issues such as individualism, secularism and the emancipation of women. The veil is used to reflect critically on notions of assimilation in western societies as well as to comment on how national identities are prioritized over religious ethnic and other identities. Another chapter considers food blogs run by South Asian diaspora to interrogate notions of community and how food through blogging performs the work of creating authentic culture. Furthermore, they function to mediate between Asian and western palates thus enacting cosmopolitanism through the gendered politics of diasporic life. Finally, there is a chapter that considers Indian music in the diaspora and how ideas of authenticity are again enacted through the training of children and others in Indian music. The chapter unravels the notion of authenticity tied to the idea of a singular origin and considers how technology (such as skype) allows for this notion of authentic Indian music.

Together these examples show well the connections between media and migration. Whilst there were moments that I felt the book could have pushed the connections between media and migration further, it represents (for me as a non-media studies scholar) a fascinating and eloquent collection. In particular, I felt the chapter on the veil could have been developed further given the extensive writing on this topic, however, read together, this is a book that offers very important insight to a migration studies audience and the interdisciplinary focus makes it original and interesting. The book is accessible without being simplistic and so can be used by academics and students alike. 